Karolin Behringer, Horst Mueller, Helen Goergen, Indra Thielen, Angelika Diana Eibl, Volker Stumpf, Carsten Wessels, Martin Wiehlpütz, Johannes Rosenbrock, Teresa Halbsguth, Katrin S. Reiners, Thomas Schober, Michael Fuchs, Volker Diehl, Andreas Engert, and Peter Borchmann, University Hospital of Cologne; Jorg H. Renno, Institute for Clinical Chemistry, University of Cologne, Cologne; Katrin van der Ven and Marietta Kuehr, University of Bonn, Bonn, Germany; Michael von Wolff, University Women's Hospital, Bern, Switzerland.

Published online ahead of print at www.jco.org on November 13, 2012

Written on behalf of the German Hodgkin Study Group.

Supported by the Deutsche Krebshilfe (Grant No. 109087), the Bundesministerium für Bildung und Forschung, and the Kompetenznetz Maligne Lymphome.

Presented in part at 53rd Annual Meeting of the American Society of Hematology, December 10-13, 2011, San Diego, CA.

Authors' disclosures of potential conflicts of interest and author contributions are found at the end of this article.

Corresponding author: Peter Borchmann, MD, PhD, First Department of Internal Medicine, University Hospital of Cologne, Kerpener Str 62, D-50924 Cologne, Germany; e-mail: peter borchmann@uni-koeln.de.

C 2012 by American Society of Clinical Oncology

0732-183X/13/3102-231/\$20.00

DOI: 10.1200/JCO.2012.44.372

\title{
Gonadal Function and Fertility in Survivors After Hodgkin Lymphoma Treatment Within the German Hodgkin Study Group HD13 to HD15 Trials
}

Karolin Behringer, Horst Mueller, Helen Goergen, Indra Thielen, Angelika Diana Eibl, Volker Stumpf, Carsten Wessels, Martin Wiehlpütz, Johannes Rosenbrock, Teresa Halbsguth, Katrin S. Reiners, Thomas Schober, Jorg H. Renno, Michael von Wolff, Katrin van der Ven, Marietta Kuehr, Michael Fuchs, Volker Diehl, Andreas Engert, and Peter Borchmann

\section{$\begin{array}{llllllll}\text { A } & \text { B } & \mathbf{S} & \mathbf{T} & \mathbf{R} & \mathbf{A} & \mathbf{C} & \mathbf{T}\end{array}$}

\section{Purpose}

To optimize fertility advice in patients with Hodgkin lymphoma (HL) before therapy and during survivorship, information on the impact of chemotherapy is needed. Therefore, we analyzed gonadal functions in survivors of $\mathrm{HL}$.

\section{Patients and Methods}

Women younger than age 40 and men younger than 50 years at diagnosis in ongoing remission at least 1 year after therapy within the German Hodgkin Study Group HD13 to HD15 trials for earlyand advanced-stage HL were included. Hormone parameters, menstrual cycle, symptoms of hypogonadism, and offspring were evaluated.

\section{Results}

A total of 1,323 (55\%) of 2,412 contacted female and male survivors were evaluable for the current analysis (mean follow-up, 46 and 48 months, respectively). Follicle-stimulating hormone, antiMüllerian hormone, and inhibin B levels correlated significantly with therapy intensity $(P<.001)$. Low birth rates were observed in survivors after advanced-stage treatment within the observation time (women, 6.5\%; men, 3.3\%). Regular menstrual cycle was reported by more than $90 \%$ of female survivors of early-stage $\mathrm{HL}$ (recovery time mostly $\leq 12$ months). After six to eight cycles of bleomycin, etoposide, doxorubicin, cyclophosphamide, vincristine, procarbazine, and prednisone, menstrual activity was strongly related to age $(<v \geq 30$ years: $82 \% v 45 \%$, respectively; $P<.001$; prolonged recovery time). Thirty-four percent of women age $\geq 30$ years suffered severe menopausal symptoms (three- to four-fold more frequently than expected). In contrast, male survivors had mean levels of testosterone within the normal range and reported no increased symptoms of hypogonadism.

\section{Conclusion}

The present analysis in a large group of survivors of HL provides well-grounded information on gonadal toxicity of currently used treatment regimens and allows risk-adapted fertility preservation and comprehensive support during therapy and follow-up.

\section{J Clin Oncol 31:231-239. (c) 2012 by American Society of Clinical Oncology}

\section{INTRODUCTION}

High overall survival rates (approximately 90\%) in early- and advanced-stage Hodgkin lymphoma (HL) have been achieved. ${ }^{1-3}$ Thus, current clinical research focuses on the short- and long-term sequelae in the growing number of young survivors of HL. Among these sequelae, infertility and hypogonadism are of particular importance for patients and survivors and demand specialized medical care. ${ }^{4-8}$

Health care professionals need comprehensive information on treatment-related gonadal toxicity. At diagnosis, physicians should inform the patient thoroughly and consider protective methods to preserve fertility in time. During the follow-up period, survivors need professional advice when they desire to have children. Furthermore, it is essential to detect and maybe to treat symptoms of hypogonadism. Unfortunately, these issues are still not routinely addressed by most physicians. ${ }^{5,9}$

It is known that the rate of treatment-induced infertility increases with more aggressive chemotherapy. ${ }^{10-14}$ However, there still are many open questions about the probability of amenorrhea, reduced ovarian reserve, and infertility after distinct chemotherapies and the impact of age at treatment onset, as 
well as about the chance of recovery and the risk of suffering from symptoms of hypogonadism. Thus, more detailed information is needed for both patients and physicians. Therefore, the main objective of the present analysis is to provide data on the impact of currently used chemotherapy in HL on gonadal function.

\section{PATIENTS AND METHODS}

\section{HD13 to HD15 Trials: Patients and Study Design}

Patients (age 18 to 75 years) with biopsy-proven HL were included in trials for early favorable (HD13, two cycles of doxorubicin, vinblastine, and dacarbazine with bleomycin [ABVD] or without bleomycin), early unfavorable (HD14, arm A: four cycles of ABVD or arm B: two cycles of escalated bleomycin, etoposide, doxorubicin, cyclophosphamide, vincristine, procarbazine, and prednisone [BEACOPP] followed by two cycles of ABVD [2+2]), or advanced-stage HL (HD15, six to eight cycles of escalated BEACOPP or eight cycles of BEACOPP-14). ${ }^{1-3}$ The studies were carried out in accordance with the Declaration of Helsinki and the International Conference on Harmonisation Good Clinical Practice guidelines.

\section{Assessment of Gonadal Function and Fertility}

All survivors (age at random assignment: women, 18 to 39 years; men, 18 to 49 years) in ongoing remission at least 1 year after therapy and without any other treatment than the HD13 to HD15 trial medication were addressed. In women, results were stratified with respect to age (cutoff, 30 years). ${ }^{12,15}$ In men, we interpreted inhibin $\mathrm{B}$ in the context of follicle-stimulating hormone (FSH) levels to achieve the highest positive predictive value with a cutoff for the inhibin B/FSH ratio corresponding to proven fertile men and cutoff levels for FSH and inhibin B corresponding to oligospermia. ${ }^{16,17}$

\section{Questionnaires}

Symptoms of hypogonadism were determined using the Menopause Rating Scale (MRS) and the Aging Males' Symptoms scale. ${ }^{18-21}$ Additional questions referred to the use of hormonal substitution, methods of fertility preservation before therapy, menstrual status, pregnancies and offspring after normal and in vitro fertilization, and social aspects.

\section{Hormone Analysis}

Survivors were asked to take a blood sample (samples for women were taken on day 3 of a new menstrual cycle or at the end of the pill break). Blood samples were then centrally processed and stored at $-80^{\circ} \mathrm{C}$ until analysis. Tests included standardized assays for $\mathrm{FSH}$, luteinizing hormone (LH), estradiol, and testosterone (heterogenic, noncompetitive chemiluminescent immunometric assays; Elecsys-FSH, Elecsys-LH, Elecsys-Estradiol-II, Elecsys-Testosterone-II; Roche Diagnostics, Mannheim, Germany); anti-Müllerian hormone (AMH; active AMH Gen-II ELISA; Beckman Coulter, Prague, Czech Republic); and inhibin B (inhibin B Gen-II ELISA-KIT; Beckman Coulter).

\section{Statistics}

In female survivors ( $\leq 40$ years old at first diagnosis of $\mathrm{HL}$ and $\leq 45$ years old at time of fertility assessment), results are reported in age groups (18 to 29 years and 30 to 45 years). For men, the upper age limit at time of fertility assessment was 57 years. Outcome measures of female fertility were menstrual activity, time to resumption of menstrual activity, hormone values, MRS, offspring, and pregnancies after therapy. Hormone levels were natural logtransformed before statistical computations to normalize distributions. Fertility parameters in HD15 survivors are additionally stratified for the use of gonadotropin-releasing hormone $(\mathrm{GnRH})$ analogs. Results are presented with descriptive statistics and $95 \%$ CIs. To provide a more detailed analysis of age effects in female survivors, we computed a logistic regression of amenorrhea on age, with time since end of chemotherapy as covariate. Additionally, generalized Kaplan-Meier estimates of time to resumption of menstrual activity are provided for age groups. For analyses of male survivors, FSH and LH were log-transformed before any statistical computations; inhibin B, testosterone, and the inhibin $\mathrm{B} / \mathrm{FSH}$ ratio were not transformed because these variables and their residuals showed no major deviations from normality. Correlations between hormone levels and relevant parameters such as age or follow-up time were assessed using linear regression models within treatment groups.

The level of significance was set at $P=.05$ (two-sided). Continuous parameters were tested with parametric tests for independent groups ( $t$ test, analysis of variance), categorical data were tested with exact and binomial tests, and no corrections for multiple testing were applied. All statistical analyses were computed with SAS version 9.2 (SAS Institute, Cary, NC).

\section{RESULTS}

\section{Patient Characteristics}

A total of $1,323(55 \%)$ of 2,412 contacted survivors participated (562 women and 761 men; Fig 1). In women and men, mean age at fertility assessment was 32 and 38 years, respectively, and mean observation time from the end of treatment was 46 and 48 months, respectively. Comparing all trials, there were unfavorable conditions for patients treated in the HD13 trial, with higher age at fertility assessment (women, 36 years; men, 40 years) and a higher proportion of patients having children before therapy (women, 47\%; men, 57\%). There were balanced conditions for patients treated in the HD14 and HD15 trials (Table 1). Comparison of the participating and nonparticipating patients qualifying for our analysis showed no relevant differences (Appendix Table A1, online only).

\section{Female Survivors}

Hormones in female survivors. Differences in favor of early-stage patients treated with fewer cycles (two to four instead of six to eight cycles) of less intensive chemotherapy were high and significant for $\mathrm{AMH}$ and $\mathrm{FSH}$ in both age groups $(P<.001)$. Hormone levels were

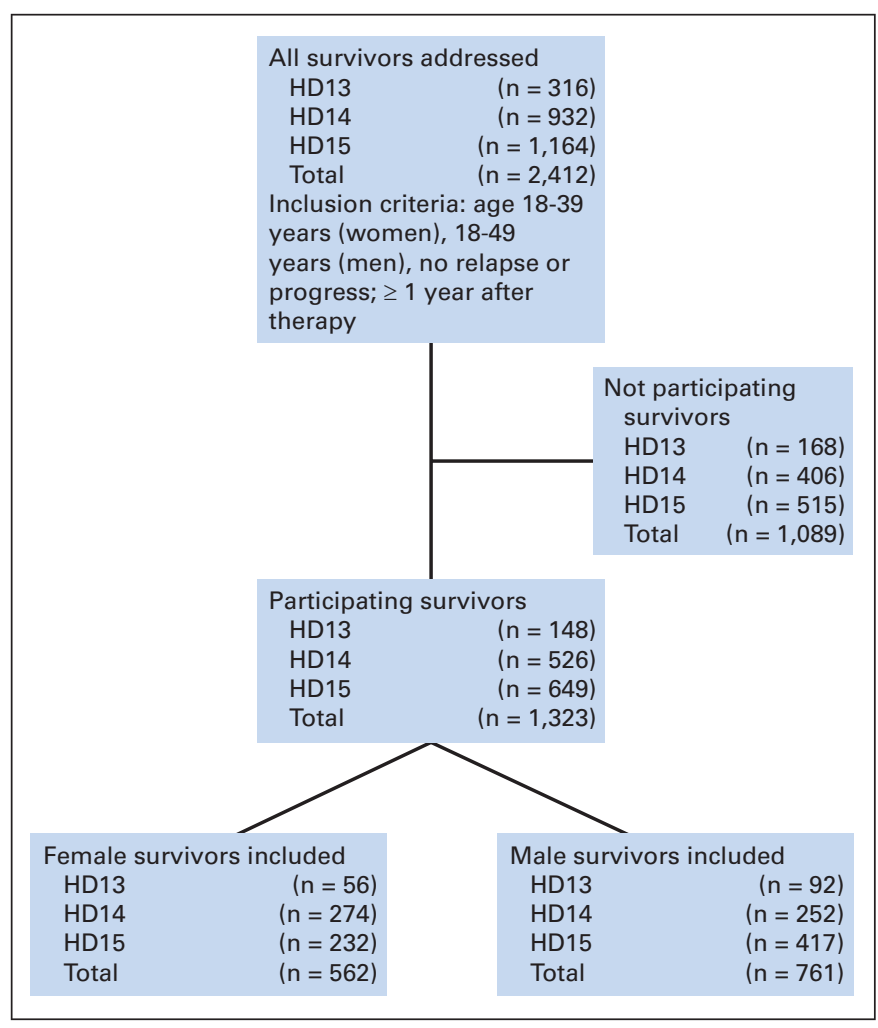

Fig 1. CONSORT diagram. 


\begin{tabular}{|c|c|c|c|c|c|c|c|c|c|c|c|c|c|c|c|c|}
\hline \multirow[b]{3}{*}{ Characteristic } & \multicolumn{8}{|c|}{ Female Patients } & \multicolumn{8}{|c|}{ Male Patients } \\
\hline & \multicolumn{2}{|c|}{ HD13 $(n=56)$} & \multicolumn{2}{|c|}{$\begin{array}{c}\text { HD14 } \\
(n=274)\end{array}$} & \multicolumn{2}{|c|}{$\begin{array}{c}\text { HD15 } \\
(n=232)\end{array}$} & \multicolumn{2}{|c|}{$\begin{array}{c}\text { Total } \\
(n=562)\end{array}$} & \multicolumn{2}{|c|}{$\begin{array}{c}\text { Total } \\
(\mathrm{n}=761)\end{array}$} & \multicolumn{2}{|c|}{$\mathrm{HD13}(\mathrm{n}=92)$} & \multicolumn{2}{|c|}{$\begin{array}{c}\text { HD14 } \\
(n=252)\end{array}$} & \multicolumn{2}{|c|}{$\begin{array}{c}\text { HD15 } \\
(n=417)\end{array}$} \\
\hline & $\begin{array}{l}\text { No./Total } \\
\text { No.* }\end{array}$ & $\% *$ & $\begin{array}{l}\text { No./Total } \\
\text { No. }\end{array}$ & $\%$ & $\begin{array}{l}\text { No./Total } \\
\text { No. }\end{array}$ & $\%$ & $\begin{array}{l}\text { No./Total } \\
\text { No. }\end{array}$ & $\%$ & $\begin{array}{l}\text { No./Total } \\
\text { No. }\end{array}$ & $\%$ & $\begin{array}{l}\text { No./Total } \\
\text { No. }\end{array}$ & $\%$ & $\begin{array}{l}\text { No./Total } \\
\text { No. }\end{array}$ & $\%$ & $\begin{array}{l}\text { No./Total } \\
\text { No. }\end{array}$ & $\%$ \\
\hline \multicolumn{17}{|l|}{$\begin{array}{l}\text { Age at fertility assessment, } \\
\text { years }\end{array}$} \\
\hline Mean & \multicolumn{2}{|l|}{35} & \multicolumn{2}{|l|}{32} & \multicolumn{2}{|l|}{32} & \multicolumn{2}{|l|}{32} & \multicolumn{2}{|l|}{38} & \multicolumn{2}{|l|}{40} & \multicolumn{4}{|c|}{38} \\
\hline Standard deviation & \multicolumn{2}{|l|}{7} & \multicolumn{2}{|l|}{7} & \multicolumn{2}{|l|}{7} & \multicolumn{2}{|l|}{7} & 9 & & 8 & & 9 & & 9 & \\
\hline Range & $21-44$ & & $20-45$ & & $20-45$ & & $20-45$ & & $19-57$ & & $21-54$ & & $19-54$ & & $20-57$ & \\
\hline Age at $\mathrm{HL}$ diagnosis, years & & & & & & & & & & & & & & & & \\
\hline Mean & 31 & & 28 & & 27 & & 28 & & 34 & & 36 & & 34 & & 33 & \\
\hline Standard deviation & 6 & & 7 & & 6 & & 7 & & 9 & & 9 & & 9 & & 9 & \\
\hline Range & $18-39$ & & $18-39$ & & $18-39$ & & $18-39$ & & $18-49$ & & $18-49$ & & $18-49$ & & $18-49$ & \\
\hline $\begin{array}{l}\text { Time from end of chemotherapy } \\
\text { months }\end{array}$ & & & & & & & & & & & & & & & & \\
\hline Mean & 45 & & 43 & & 50 & & 46 & & 48 & & 50 & & 44 & & 51 & \\
\hline Standard deviation & 23 & & 20 & & 20 & & 20 & & 20 & & 24 & & 19 & & 19 & \\
\hline Range & $12-96$ & & $12-83$ & & $12-91$ & & $12-96$ & & $12-103$ & & $12-103$ & & $12-79$ & & $12-94$ & \\
\hline Clinical stage & & & & & & & & & & & & & & & & \\
\hline । & $4 / 45$ & 9 & $10 / 274$ & 4 & & & $14 / 549$ & 2 & $36 / 736$ & 5 & $25 / 68$ & 37 & $11 / 251$ & 4 & & \\
\hline ॥ & $41 / 45$ & 91 & $260 / 274$ & 96 & $59 / 230$ & 26 & $364 / 549$ & 66 & $341 / 736$ & 46 & $43 / 68$ & 63 & $240 / 251$ & 96 & $58 / 417$ & 14 \\
\hline III & & & & & $105 / 230$ & 46 & $105 / 549$ & 19 & $225 / 736$ & 31 & & & & & $225 / 417$ & 54 \\
\hline IV & & & & & $66 / 230$ & 29 & $66 / 549$ & 12 & $134 / 736$ & 18 & & & & & $134 / 417$ & 32 \\
\hline "B" symptoms present & $7 / 45$ & 16 & $56 / 274$ & 20 & $145 / 230$ & 63 & $208 / 549$ & 38 & $362 / 736$ & 49 & $8 / 68$ & 12 & $81 / 251$ & 32 & $273 / 417$ & 66 \\
\hline Chemotherapy & & & & & & & & & & & & & & & & \\
\hline Two cycles of $A(B) V D$ & $56 / 56$ & 100 & & & & & $56 / 562$ & 10 & $92 / 761$ & 12 & $92 / 92$ & 100 & & & & \\
\hline Four cycles of ABVD & & & $139 / 274$ & 51 & & & $139 / 562$ & 25 & 120/761 & 16 & & & $120 / 252$ & 48 & & \\
\hline $2+2$ & & & $135 / 274$ & 49 & & & $132 / 562$ & 23 & $132 / 761$ & 17 & & & $132 / 252$ & 52 & & \\
\hline $\begin{array}{l}\text { Eight cycles of escalated } \\
\text { BEACOPP }\end{array}$ & & & & & 79/232 & 34 & $79 / 562$ & 14 & $142 / 761$ & 19 & & & & & $142 / 417$ & 34 \\
\hline $\begin{array}{l}\text { Six cycles of escalated } \\
\text { BEACOPP }\end{array}$ & & & & & 75/232 & 32 & $75 / 562$ & 13 & 146/761 & 19 & & & & & $146 / 417$ & 35 \\
\hline Eight cycles of BEACOPP-14 & & & & & $79 / 232$ & 34 & $79 / 562$ & 14 & $129 / 761$ & 17 & & & & & $129 / 417$ & 31 \\
\hline Parenthood before, yes & $23 / 49$ & 47 & $96 / 255$ & 38 & $85 / 219$ & 39 & $204 / 523$ & 39 & $323 / 705$ & 46 & $50 / 88$ & 57 & $101 / 233$ & 43 & $172 / 384$ & 45 \\
\hline Oral contraception, yes & $15 / 54$ & 28 & $86 / 268$ & 32 & $46 / 231$ & 20 & $147 / 553$ & 27 & & & & & & & & \\
\hline GnRH, yes & $10 / 54$ & 19 & $62 / 268$ & 23 & $77 / 231$ & 33 & $149 / 553$ & 27 & & & & & & & & \\
\hline Oral contraception now, yes & $25 / 54$ & 46 & $131 / 268$ & 49 & $134 / 231$ & 58 & $290 / 553$ & 52 & & & & & & & & \\
\hline $\begin{array}{l}\text { Cryopreservation of sperm (men) } \\
\text { or oocytes or ovarian tissue } \\
\text { (women) yest }\end{array}$ & $3 / 52$ & 6 & $21 / 257$ & 8 & $20 / 214$ & 8 & $44 / 523$ & 9 & $274 / 724$ & 38 & $26 / 88$ & 30 & $101 / 239$ & 42 & $147 / 397$ & 37 \\
\hline Sex partner now, yes & $52 / 55$ & 95 & $240 / 265$ & 91 & $174 / 219$ & 80 & $466 / 539$ & 87 & $593 / 713$ & 83 & $76 / 86$ & 88 & $197 / 236$ & 84 & $320 / 391$ & 82 \\
\hline $\begin{array}{l}\text { Abbreviations: A(B)VD, doxorub } \\
\text { cyclophosphamide, vincristine, } \\
\text { followed by two cycles of ABVD. } \\
\text { "Total No. represents number of } \\
\text { tCryopreservation of fertilized } \\
\text { cryopreservation of ovarian tissue }\end{array}$ & $\begin{array}{l}\text { in, (bleomy } \\
\text { carbazine, } \\
\text { patients wit } \\
\text { ocytes, } n= \\
n=16 \text {; cry }\end{array}$ & $\begin{array}{l}\text { (cin), } \\
\text { and pre } \\
\text { h valid } \\
6 \text {; cr }\end{array}$ & $\begin{array}{l}\text { vinblastine, } \\
\text { ednisone; } \\
\text { data, and } \\
\text { yopreserva } \\
\text { ervation of }\end{array}$ & $\begin{array}{l}\text { GnR } \\
\text { perce } \\
\text { ation }\end{array}$ & $\begin{array}{l}\text { dacarbazir } \\
\text {, gonadotr } \\
\text { entages rep } \\
\text { of unfertili } \\
\text { oocytes an }\end{array}$ & $\begin{array}{l}\text { ine; } \\
\text { ropin- } \\
\text { prese } \\
\text { ized } \\
\text { nd ov }\end{array}$ & $\begin{array}{l}\text { ART, assis } \\
\text {-releasing } \\
\text { ent percent } \\
\text { oocytes, n } \\
\text { garian tissue }\end{array}$ & $\begin{array}{l}\text { ted } r \\
\text { horm } \\
\text { ages } \\
\text { age } 11\end{array}$ & $\begin{array}{l}\text { reproductior } \\
\text { hone; } H L, H \\
\text { of patients } \\
1 ; \text { cryopres }\end{array}$ & & $\begin{array}{l}\text { EACOPP, } \\
\text { kin lympho } \\
\text { h valid data } \\
\text { tion of oo }\end{array}$ & $\begin{array}{l}\text { bleom } \\
\text { ma; } 2 \\
\text { a. }\end{array}$ & $\begin{array}{l}\text { nycin, etopo } \\
2+2 \text {, two cy } \\
\text { not further } \\
\text { rther specifi }\end{array}$ & $\begin{array}{l}\text { oside } \\
\text { sycles } \\
\text { er sp } \\
\text { fied, }\end{array}$ & $\begin{array}{l}\text { e, doxorubi } \\
\text { s of BEACC } \\
\text { ecified, } n= \\
n=6\end{array}$ & \\
\hline
\end{tabular}

different with respect to age; mean AMH levels greater than $2 \mu \mathrm{g} / \mathrm{L}$ were only observed in women younger than 30 years after ABVD therapy (Table 2). After HD15 therapy, mean AMH levels were $0 \mu \mathrm{g} / \mathrm{L}$ in both age groups, and the highest FSH levels were measured (mean FSH: $<30$ years, 11.1 U/L; $\geq 30$ years, $29.7 \mathrm{U} / \mathrm{L})$. Serum levels of $\mathrm{AMH}$ and FSH differed between treatment groups in the HD14 trial. These differences in favor of ABVD were high and significant for FSH in older women (mean FSH in women age 30 to 45 years: arm A, 4.4 $\mathrm{U} / \mathrm{L}$; $\operatorname{arm} \mathrm{B}, 11.8 \mathrm{U} / \mathrm{L} ; P<.001)$ and for $\mathrm{AMH}$ in both age groups (mean AMH in women age $<30$ years: arm A, $2.3 \mu \mathrm{g} / \mathrm{L}$; arm B, 0.9 $\mu \mathrm{g} / \mathrm{L} ; P<.001 ;$ mean $\mathrm{AMH}$ in women age $\geq 30$ years: arm $\mathrm{A}, 0.7$ $\mu \mathrm{g} / \mathrm{L} ; \operatorname{arm~B}, 0.0 \mu \mathrm{g} / \mathrm{L} ; P<.001) .{ }^{22}$ In contrast, no difference was found between the three BEACOPP arms of the HD15 trial $(P>.15)$.
Regular cycle and time to resumption of menstrual activity. In both age groups, more than $90 \%$ of survivors after treatment for early-stage HL reported a regular cycle after therapy, and time to resumption of menstrual activity was mostly reached within 1 year (Fig 2A). After treatment for advanced-stage HL, 82\% of women younger than 30 years had a regular cycle, compared with only $45 \%$ of women in the older age group (Table 2). There was no difference regarding whether or not women had received cotreatment with GnRH analogs. Time to resumption of menstrual activity took considerably longer than in early-stage patients and was strongly related to age (Fig 2A). The mean age of women with sustained amenorrhea was 31.6 years at start of chemotherapy ( $95 \%$ CI, 30.5 to 32.8 years), whereas the mean age of women with a regular cycle was 27.1 years 
Table 2. Fertility Parameters of Female Survivors After Six Randomly Assigned Treatments in Two Age Groups (18 to 29 years and 30 to 45 years)

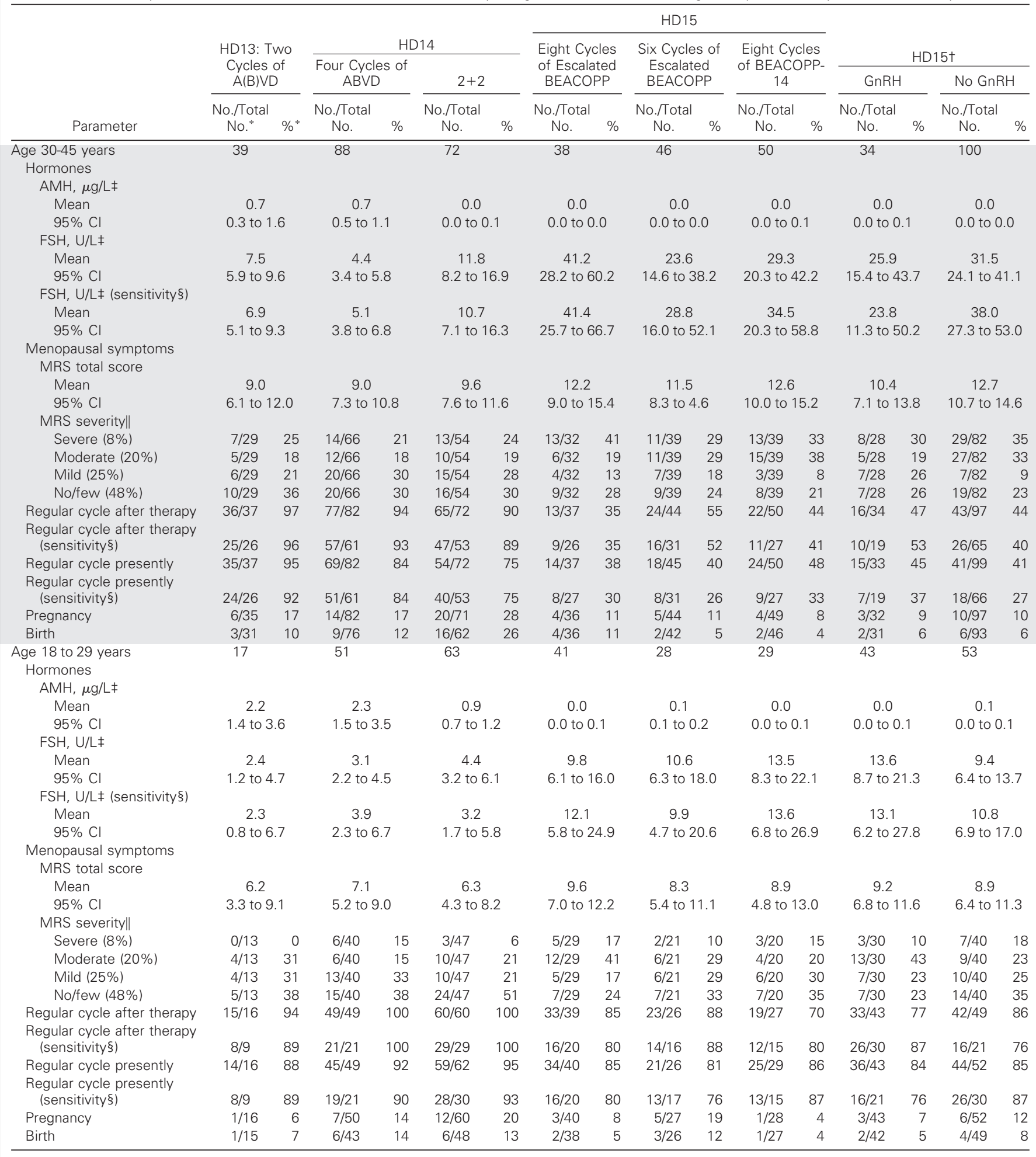

Abbreviations: $A(B) V D$, doxorubicin, (bleomycin), vinblastine, and dacarbazine; $\mathrm{AMH}$, anti-Müllerian hormone; BEACOPP, bleomycin, etoposide, doxorubicin, cyclophosphamide, vincristine, procarbazine, and prednisone; FSH, follicle-stimulating hormone; GnRH, gonadotropin-releasing hormone; MRS, Menopause Rating Scale; $2+2$, two cycles of BEACOPP followed by two cycles of ABVD.

*Total No. represents number of patients with valid data, and percentages represent percentages of patients with valid data.

tSurvivors of the HD15 study grouped according to (nonrandomized) treatment with GnRH.

¥All computations for AMH and FSH are log-transformed values to normalize distributions; table entries are in original units (after exponentiation).

$\S$ Sensitivity analysis in a subgroup of survivors who did not take oral contraceptives/hormone replacement therapy.

\|Classification of MRS total score with reference scores for 45- to 60-year-old German women in parentheses. 


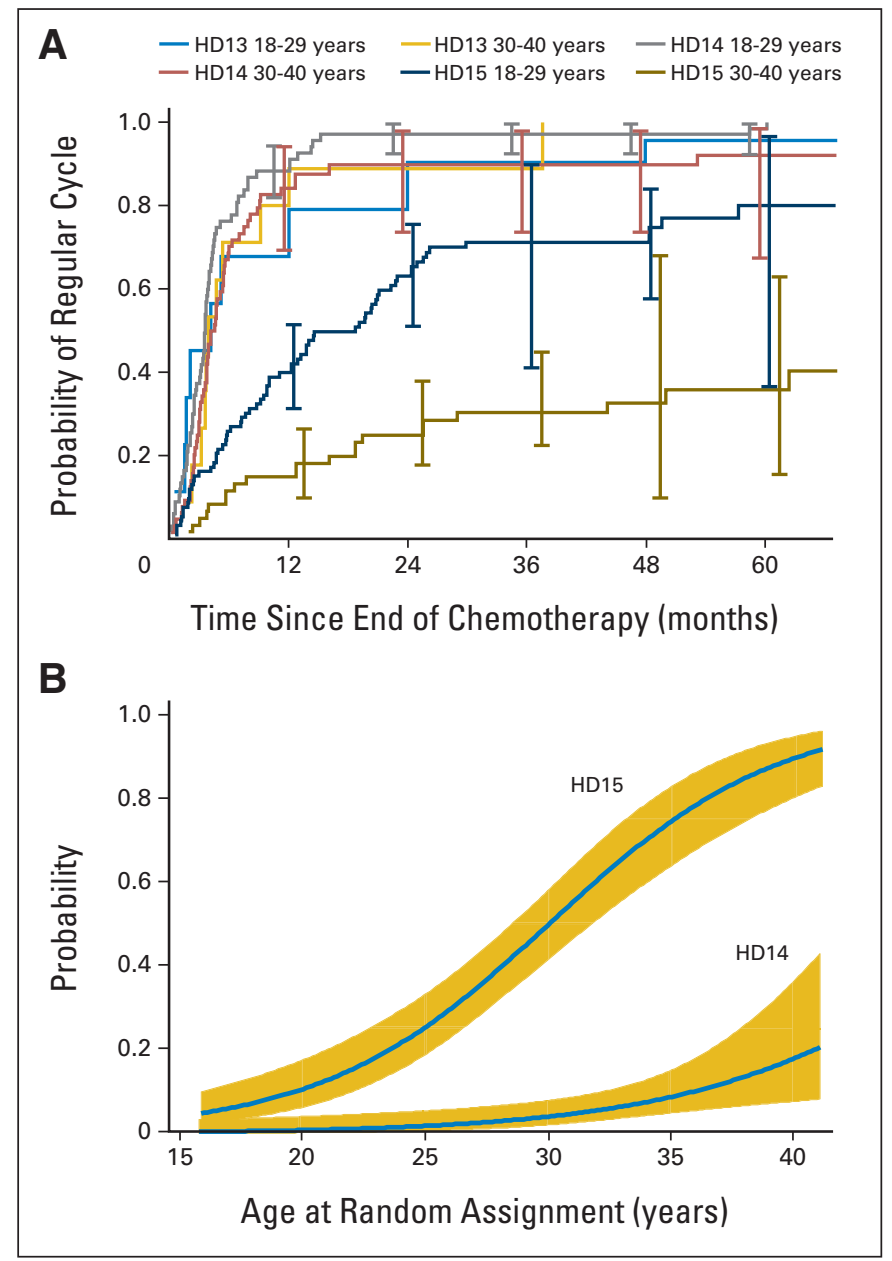

Fig 2. (A) Time to regular cycle in the three trials and two age groups. Generalized Kaplan-Meier estimates shown with 90\% Cls for HD14 and HD15. (B) Probability of amenorrhea 4 years after chemotherapy; the significant influence of age at therapy is shown (estimates of logistic regression analyses for HD15 and HD14 at the mean time after chemotherapy, 47 months, with $90 \%$ Cls).

(95\% CI, 26.5 to 27.7 years). In advanced-stage patients, the risk of amenorrhea 4 years after chemotherapy highly correlated with age at HL diagnosis $(25$ years $=25 \%$ risk; 30 years $=50 \%$ risk; Fig $2 \mathrm{~B}$ ). In the HD15 trial, only three (9\%) of 35 women older than 35 years at start of chemotherapy reported a regular cycle after therapy, and in arms A and B, after six to eight cycles of escalated BEACOPP, only one (4\%) of 23 survivors reported a regular cycle.

\section{Pregnancies and Offspring}

In contrast to women after treatment for early-stage HL, fewer pregnancies were reported in women after treatment for advancedstage HL (HD13 + HD14, $\mathrm{n}=60,19 \%$; HD15, $\mathrm{n}=22,10 \%$; Table 2). After HD15 therapy, $51.9 \%$ of female survivors reported a desire to have children, but only $15 \%$ reported parenthood at 4 years. In advanced-stage patients, GnRH analogs had no influence on pregnancies after therapy in contrast to observed results after treatment for early unfavorable HL. ${ }^{22}$

Menopausal symptoms. MRS total score showed no significant difference between HL trials regarding menopausal symptoms in women $\leq 30$ years. An age-related increase of severe menopausal symptoms was observed in all trials. Severe symptoms were four- to five-fold more frequent in women $\geq 30$ years after therapy for advanced-stage HL compared with a 45- to 60-year-old German reference cohort (Table 2 ). MRS correlated significantly with menstrual activity $(P<.001)$, as well as with LH and FSH levels $(P<.001)$. Only $48.9 \%$ of women with severe symptoms were on hormone medication at the time of the survey.

\section{Male Survivors}

Hormones in male survivors. Serum levels of inhibin B and FSH were significantly different between trials in favor of early-stage patients treated with fewer cycles (two to four instead of six to eight cycles) of less intensive chemotherapy $(P<.001)$. Importantly, in the HD14 trial, FSH and inhibin B values differed significantly between treatment arms in favor of ABVD. No difference was found between the three BEACOPP regimens in HD15 (Table 3).

With few exceptions, inhibin B and FSH levels corresponding to proven fertility (inhibin B/FSH ratio $>23.5 \mathrm{ng} / \mathrm{U}$ ) were only seen after ABVD or 2+2 (HD13, 51.2\%; HD14, 50.4\%; HD15, 0.5\%). The highest proportions of inhibin $\mathrm{B}$ and $\mathrm{FSH}$ levels corresponding to oligospermia (inhibin $\mathrm{B}<80 \mathrm{ng} / \mathrm{L}$ and $\mathrm{FSH}>10 \mathrm{U} / \mathrm{L}$ ) were measured after BEACOPP (HD13, 12.2\%; HD14, 20.7\%; HD15, 88.8\%; Fig 3A). LH levels increased significantly with disease stage (highest mean value of 7.3 U/L after HD15 treatment; normal range, 1.7 to 8.6 $\mathrm{U} / \mathrm{L})$. Mean testosterone levels were within the normal range of 2.8 to $8.0 \mathrm{ng} / \mathrm{L}$ after all treatment regimens (Table 3).

Effect of follow-up time and age on inhibin B and FSH levels. A significant effect of follow-up time on inhibin B and FSH levels, indicating a recovery of spermatogenesis, was found after treatment with the $2+2$ regimen $(P<.001)$. Overall, in the HD14 trial, these hormone levels differed significantly in favor of four cycles of $\operatorname{ABVD}(P<.001)$; however, the subgroup of survivors with a follow-up of $\geq 4$ years showed similar hormone levels in both treatment groups (Fig 4). No recovery was found in survivors of advanced-stage HL. There was an effect of age in all three trials, with favorable hormone levels in younger survivors (HD13: $P=.08$; HD14: $P<.001$; HD15: $P<.001$; data not shown).

Effect of age on testosterone. In survivors after HD14 and HD15 treatment, a significant age effect was found, with higher testosterone levels in younger men (HD14: $P=.002$; HD15: $P<.001$ ). In a multivariate analysis adjusting for the effect of study, age remained an independent predictor of testosterone value (data not shown).

Utilization of cryopreserved sperm, birth rate, and children after therapy. The birth rate after treatment in the HD 15 trial was significantly lower compared with after treatment for early stages (study comparison: $P=.04$ ). Children after natural fertilization were most frequently reported in survivors after early-stage therapy compared with advancedstage therapy (22 v two children, respectively, in HD15; Fig 3B). Two hundred seventy-four male survivors (38\%) underwent a cryopreservation of sperm before therapy (Table 1). The proportion was highest (71\%) in 18- to 29-year-old men. Twenty-six of these survivors (10\%) used their cryopreserved sperm for assisted reproduction (21 survivors of advanced-stage HL). Thirty-two percent of male survivors after HD15 therapy reported desire for children, but only $12 \%$ reported parenthood at a median follow-up time of 4 years.

Aging Males' Symptoms scale. Aging male symptoms were not different between patients in the trials and reference values (Table 3). No correlation between symptoms and hormonal levels, especially testosterone, was found. 


\begin{tabular}{|c|c|c|c|c|c|c|c|c|c|c|c|c|c|c|}
\hline \multirow[b]{3}{*}{ Parameter } & \multirow{2}{*}{\multicolumn{2}{|c|}{$\begin{array}{l}\text { HD13: Two } \\
\text { Cycles of } \\
\text { A(B)VD } \\
(n=92) \\
\end{array}$}} & \multicolumn{4}{|c|}{ HD14 } & \multicolumn{6}{|c|}{ HD15 } & \multirow{2}{*}{\multicolumn{2}{|c|}{ Total $(\mathrm{N}=761)$}} \\
\hline & & & $\begin{array}{r}\text { Four Cycl } \\
\text { ABVD } \\
(n=12 \\
\end{array}$ & $\begin{array}{l}\mathrm{HL} \\
\mathrm{s} \text { of } \\
\end{array}$ & \multicolumn{2}{|c|}{$2+2(n=132)$} & \multicolumn{2}{|c|}{$\begin{array}{c}\text { Eight Cycles of } \\
\text { Escalated } \\
\text { BEACOPP } \\
(n=142)\end{array}$} & \multicolumn{2}{|c|}{$\begin{array}{c}\text { Six Cycles of } \\
\text { Escalated } \\
\text { BEACOPP } \\
(n=146) \\
\end{array}$} & \multicolumn{2}{|c|}{$\begin{array}{l}\text { Eight Cycles of } \\
\text { BEACOPP-14 } \\
(n=129)\end{array}$} & & \\
\hline & $\begin{array}{l}\text { No./Total } \\
\text { No.* }\end{array}$ & $\%^{*}$ & $\begin{array}{l}\text { No./Total } \\
\text { No. }\end{array}$ & $\%$ & $\begin{array}{l}\text { No./Total } \\
\text { No. }\end{array}$ & $\%$ & $\begin{array}{l}\text { No./Total } \\
\text { No. }\end{array}$ & $\%$ & $\begin{array}{l}\text { No./Total } \\
\text { No. }\end{array}$ & $\%$ & $\begin{array}{l}\text { No./Total } \\
\text { No. }\end{array}$ & $\%$ & $\begin{array}{l}\text { No./Total } \\
\text { No. }\end{array}$ & $\%$ \\
\hline \multicolumn{15}{|l|}{ Hormones } \\
\hline \multicolumn{15}{|l|}{$\mathrm{FSH}, \mathrm{U} / \mathrm{L}$} \\
\hline Mean & \multirow{2}{*}{\multicolumn{2}{|c|}{$\begin{array}{c}5.6 \\
4.8 \text { to } 6.6\end{array}$}} & \multicolumn{2}{|c|}{4.4} & \multicolumn{2}{|c|}{7.9} & \multicolumn{2}{|l|}{19.2} & \multicolumn{2}{|l|}{18.7} & \multicolumn{2}{|c|}{19.0} & \multicolumn{2}{|l|}{11.0} \\
\hline $95 \% \mathrm{Cl}$ & & & \multicolumn{2}{|c|}{3.9 to 4.9} & \multicolumn{2}{|c|}{6.8 to 9.1} & \multicolumn{2}{|c|}{17.6 to 21.0} & \multicolumn{2}{|c|}{17.3 to 20.3} & \multicolumn{2}{|c|}{17.4 to 20.8} & 10.3 to 11 & \\
\hline$>12.4 \mathrm{U} / \mathrm{L}$ & $11 / 84$ & 13 & $7 / 116$ & 6 & $38 / 130$ & 29 & $105 / 128$ & 82 & $109 / 137$ & 80 & $95 / 113$ & 84 & $365 / 708$ & 52 \\
\hline Inhibin $B$, ng/L & & & & & & & & & & & & & & \\
\hline Mean & 126. & & 162.5 & & 93.9 & & 15.9 & & 16.9 & & 15.4 & & 67.2 & \\
\hline $95 \% \mathrm{Cl}$ & 111.5 to & 40.7 & 149.1 to 1 & 6.0 & 80.5 to & 07.2 & 11.3 to 2 & & 12.9 to 2 & & 11.4 to 1 & & 61.4 to 7 & \\
\hline$<25 \mathrm{ng} / \mathrm{L}$ & $6 / 82$ & 7 & $4 / 117$ & 3 & 28/130 & 22 & 100/130 & 77 & 104/139 & 75 & $80 / 112$ & 71 & $322 / 710$ & 45 \\
\hline Inhibin B/FSH ratio, ng/U & & & & & & & & & & & & & & \\
\hline Mean & 33.4 & & 49.1 & & 25.8 & & 1.5 & & 1.5 & & 1.4 & & 17.5 & \\
\hline $95 \% \mathrm{Cl}$ & 26.0 to & & 41.3 to 5 & & 18.7 to & & 0.8 to 2 . & & 1.0 to 2 & & 0.9 to 1 & & 15.1 to 2 & \\
\hline $\mathrm{LH}, \mathrm{U} / \mathrm{L}$ & & & & & & & & & & & & & & \\
\hline Mean & 4.8 & & 4.2 & & 5.1 & & 7.4 & & 7.0 & & 7.5 & & 5.9 & \\
\hline $95 \% \mathrm{Cl}$ & 4.3 to & & 3.8 to 4 & & 4.6 to & & 6.7 to 8 & & 6.6 to 7 & & 6.9 to $\varepsilon$ & & 5.7 to 6 & \\
\hline$>8.6 \mathrm{U} / \mathrm{L}$ & $9 / 84$ & 11 & $7 / 116$ & 6 & $17 / 130$ & 13 & $49 / 129$ & 38 & $38 / 136$ & 28 & $41 / 113$ & 36 & $161 / 708$ & 23 \\
\hline Testosterone, ng/L & & & & & & & & & & & & & & \\
\hline Mean & 4.2 & & 4.8 & & 4.7 & & 3.9 & & 4.1 & & 4.3 & & 4.3 & \\
\hline $95 \% \mathrm{Cl}$ & 3.9 to & & 4.5 to 5 & & 4.4 to 5 & & 3.6 to 4. & & 3.8 to 4 & & 4.0 to 4 & & 4.2 to 4. & \\
\hline$<2.8 \mathrm{ng} / \mathrm{L}$ & $17 / 84$ & 20 & $17 / 116$ & 15 & $18 / 130$ & 14 & $36 / 129$ & 28 & $29 / 137$ & 21 & $17 / 113$ & 15 & $134 / 709$ & 19 \\
\hline $\begin{array}{l}\text { Aging Males' Symptoms } \\
\text { scale }\end{array}$ & & & & & & & & & & & & & & \\
\hline Total score & & & & & & & & & & & & & & \\
\hline Mean & 30.8 & & 29.0 & & 30.4 & & 32.6 & & 29.6 & & 30.8 & & 30.6 & \\
\hline $95 \% \mathrm{Cl}$ & 28.2 to & & 26.8 to 3 & & 28.3 to 3 & & 30.4 to 3 & & 27.8 to 3 & & 28.6 to 3 & & 29.7 to 3 & \\
\hline Impairment† & & & & & & & & & & & & & & \\
\hline No $(45 \%)$ & $42 / 90$ & 47 & $62 / 111$ & 56 & $57 / 125$ & 46 & $57 / 130$ & 44 & $67 / 140$ & 48 & $50 / 116$ & 43 & $335 / 712$ & 47 \\
\hline Little (37\%) & $19 / 90$ & 21 & $25 / 111$ & 23 & $42 / 125$ & 34 & $32 / 130$ & 25 & $39 / 140$ & 28 & $36 / 116$ & 31 & $193 / 712$ & 27 \\
\hline Moderate (11\%) & $18 / 90$ & 20 & $17 / 111$ & 15 & $13 / 125$ & 10 & $24 / 130$ & 19 & $27 / 140$ & 19 & $19 / 116$ & 16 & $118 / 712$ & 17 \\
\hline Severe $(7 \%)$ & $11 / 90$ & 12 & $7 / 111$ & 6 & $13 / 125$ & 10 & $17 / 130$ & 13 & $7 / 140$ & 5 & $11 / 116$ & 10 & $66 / 712$ & 9 \\
\hline $\begin{array}{l}\text { Utilization of cryopreserved } \\
\text { sperm for ART, yes }\end{array}$ & $3 / 26$ & 12 & $0 / 48$ & 0 & $1 / 53$ & 2 & $8 / 47$ & 17 & $7 / 54$ & 13 & $7 / 46$ & 15 & $26 / 274$ & 10 \\
\hline Reproduction after therapy & & & & & & & & & & & & & & \\
\hline $\begin{array}{l}\text { Birth after natural } \\
\quad \text { fertilization }\end{array}$ & 7/76 & 9 & $11 / 104$ & 11 & $4 / 112$ & 4 & $0 / 117$ & 0 & 2/131 & 2 & 0/112 & 0 & $24 / 652$ & 4 \\
\hline $\begin{array}{l}\text { Natural fertilization, but no } \\
\text { birth (yet) }\end{array}$ & $2 / 76$ & 3 & $2 / 104$ & 2 & $2 / 112$ & 2 & $2 / 117$ & 2 & $1 / 131$ & 1 & $0 / 112$ & 0 & 9/652 & 1 \\
\hline Birth after ART & $0 / 76$ & 0 & 0/104 & 0 & $0 / 112$ & 0 & $4 / 117$ & 3 & $3 / 131$ & 2 & $3 / 112$ & 3 & $10 / 652$ & 2 \\
\hline ART, but no birth (yet) & $1 / 76$ & 1 & 0/104 & 0 & $0 / 112$ & 0 & $4 / 117$ & 3 & $3 / 131$ & 2 & $4 / 112$ & 4 & $12 / 652$ & 2 \\
\hline
\end{tabular}

\section{DISCUSSION}

With a total of 1,323 survivors of HL treated within the German Hodgkin Study Group HD13 to HD15 trials, to our knowledge, this is the largest detailed study on gonadal function and fertility after chemotherapy reported so far. The following major findings emerge from this analysis:

First, as expected, hormone levels correlate with the intensity of chemotherapy. In women, age was also a relevant factor for a reduced ovarian reserve. Normal mean AMH levels ( $>2 \mu \mathrm{g} / \mathrm{L}$ ) were observed in women younger than 30 years after two to four cycles of ABVD early-stage treatment, but AMH levels were compromised in survivors $\geq 30$ years old. After treatment with six to eight cycles of BEACOPP, mean AMH levels were $0 \mu \mathrm{g} / \mathrm{L}$ in both age groups, and the highest FSH levels were measured in women older than 30 years.

In men, half of the survivors after early-stage treatment had FSH and inhibin B levels corresponding to proven fertile men, whereas 


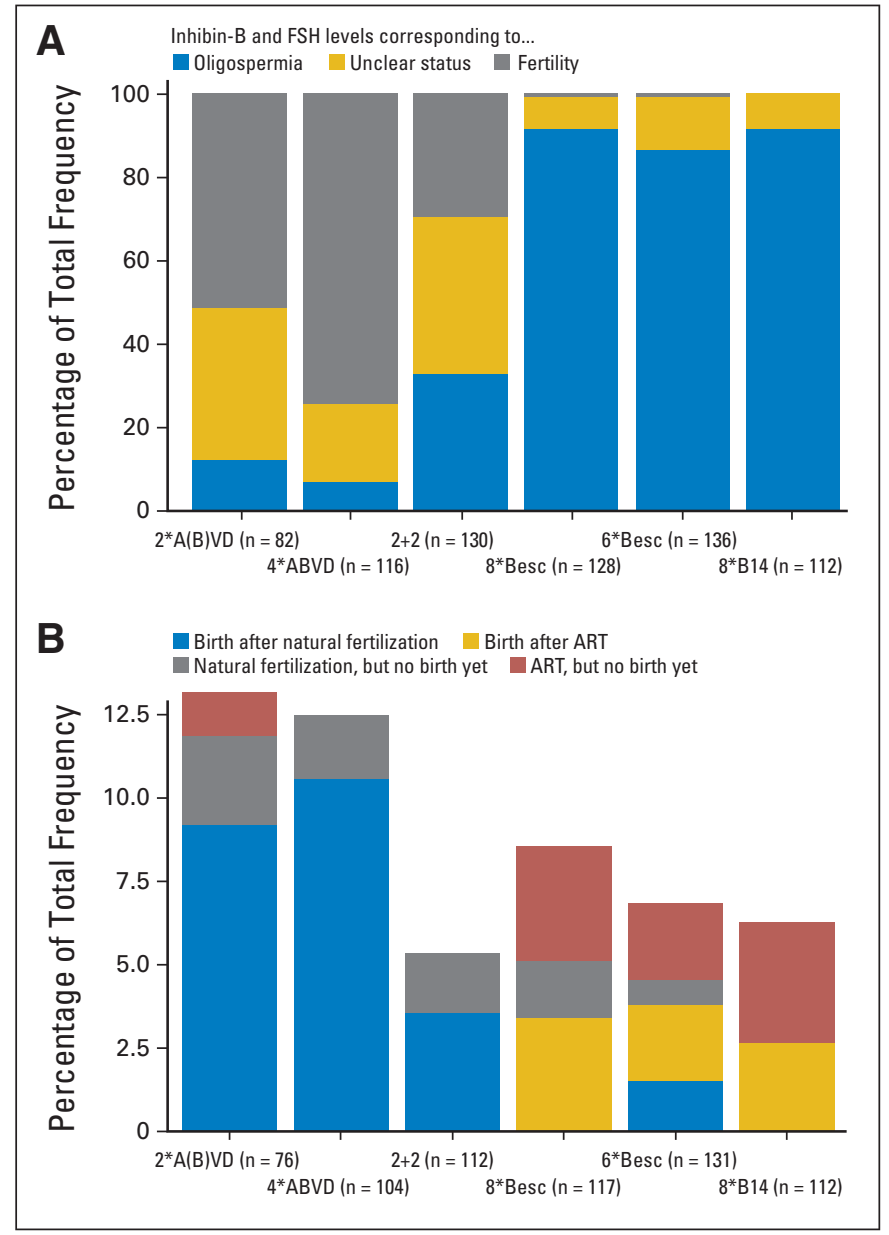

Fig 3. (A) Inhibin B and follicle-stimulating hormone (FSH) levels corresponding to proven fertility or to oligospermia in the three trials. (B) Reproduction in male survivors according to the three trials. $A(B) V D$, doxorubicin, (bleomycin), vinblastine, and dacarbazine; ART, assisted reproduction; $B$, bleomycin, etoposide, doxorubicin, cyclophosphamide, vincristine, procarbazine, and prednisone (BEACOPP); Besc, escalated BEACOPP; 2+2, two cycles of BEACOPP followed by two cycles of ABVD.

$88.8 \%$ of survivors after advanced-stage treatment had levels corresponding to oligospermia. An effect of follow-up time on inhibin B and FSH levels was found in men after $2+2$ treatment, suggesting a recovery up to 4 years after intermediate aggressive therapies. In contrast to the dose-dependent effect on the spermatogenesis as indicated by FSH and inhibin B, mean testosterone levels were within the normal range also after eight cycles of escalated BEACOPP.

Second, recovery of regular cycle was reported by more than $90 \%$ of women after early-stage treatment and was mostly completed within 1 year. In contrast, after treatment for advanced-stage HL, age at therapy onset was a decisive factor, and time to resumption of menstrual activity was considerably longer.

Third, compared with survivors after early-stage therapy, lower birth rates were observed in survivors after advanced-stage therapy (women: 15\% v 6.5\%, respectively; men: 7.2\% v 3.3\%, respectively). Of $52 \%$ of women and $32 \%$ of men with desire for children, only $15 \%$ and $12 \%$ reported parenthood within a median observation time of 4 years after advanced-stage therapy, respectively. Finally, female survivors older than age 30 years at diagnosis suffered three- to four-fold

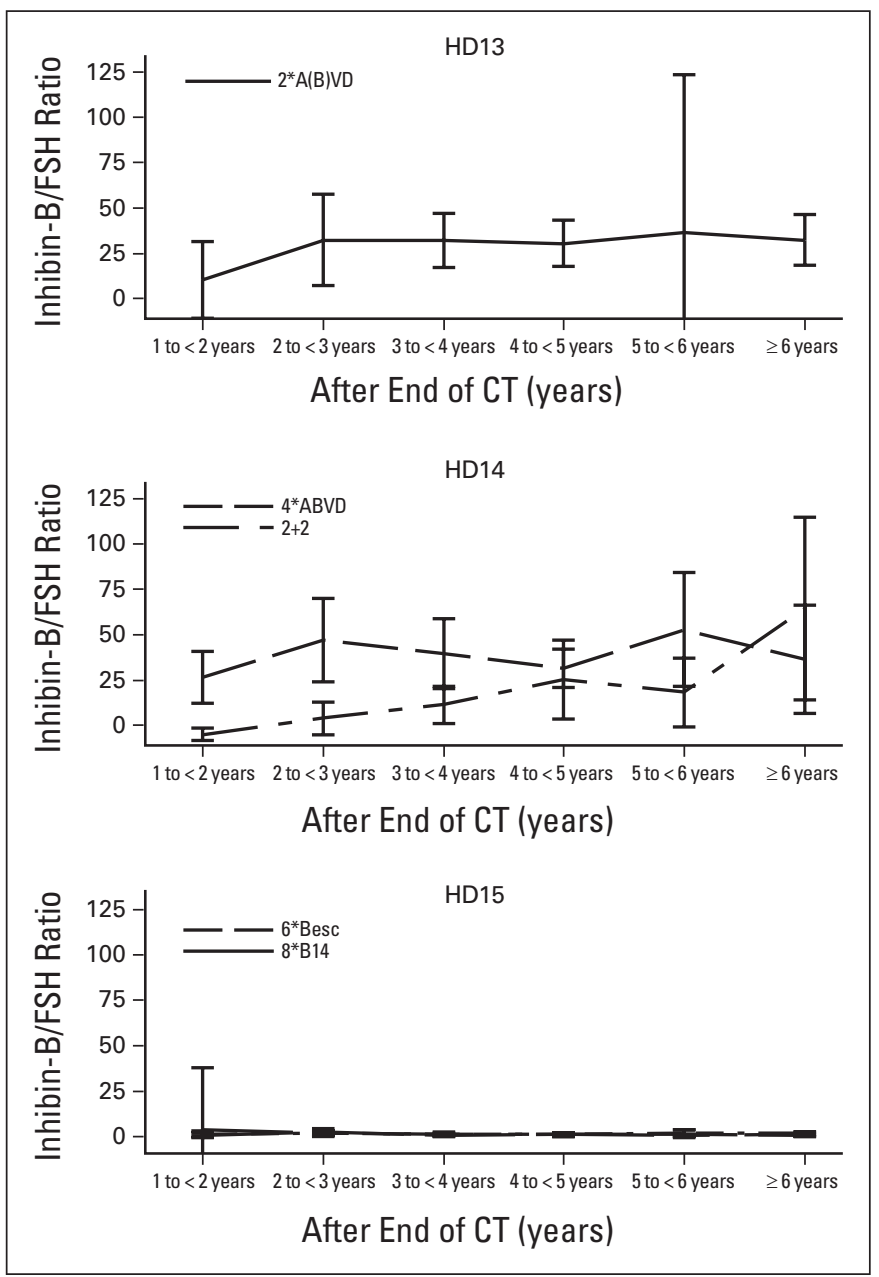

Fig 4. Effect of follow-up time on the inhibin B/follicle-stimulating hormone (FSH) ratio in the three trials. $A(B) V D$, doxorubicin, (bleomycin), vinblastine, and dacarbazine; B, bleomycin, etoposide, doxorubicin, cyclophosphamide, vincristine, procarbazine, and prednisone (BEACOPP); Besc, escalated BEACOPP; CT, chemotherapy; 2+2, two cycles of BEACOPP followed by two cycles of ABVD.

more frequently from severe menopausal symptoms compared with a 45- to 60-year-old German reference cohort.

The present analysis combines information from hormonal analyses with clinical data from large controlled trials and data obtained from standardized self-reported questionnaires. A portion of survivors did not respond, which might cause a bias. However, all information from our original trials indicated no major differences between participants and nonparticipants (Appendix Table A1). Also, comparable participation rates in all trials indicate a high external validity. We focused this analysis on the first years after chemotherapy, because gonadal toxicity, recovery, and finally parenthood are relevant problems within a limited time frame, especially for women.

As expected, chemotherapy-induced gonadal toxicity was highest after six to eight cycles of escalated BEACOPP(-14) in both female and male survivors of HL. After this regimen, hormonal levels reflect reduced ovarian reserve and amenorrhea indicates impaired fertility in the majority of women, and a relevant impairment of spermatogenesis occurred in the majority of men. However, in advanced-stage HL, aggressive therapy results in the highest overall survival rates reported 
in large prospective trials. ${ }^{1-3}$ Thus, balancing efficacy and toxicity is a difficult task for both patients and physicians. The detailed information from our analysis might contribute to a well-balanced shared decision-making process.

In women with cancer, AMH has been investigated as presumably valuable cycle-independent marker of the ovarian reserve. ${ }^{23-30}$ In our analysis, AMH levels were significantly worse after more intensive alkylating agent-containing chemotherapy and with older age. This was also true for FSH values; however, FSH showed a better differentiation between the group of women with a regular cycle and the group suffering from amenorrhea after therapy. Additionally, in women younger than 30 years after advanced-stage HL, the mean AMHlevel was $0 \mu \mathrm{g} / \mathrm{L}$. However, we observed pregnancies in women with low or even undetectable AMH levels, as previously reported in women without history of cancer. ${ }^{31,32}$ These findings underline the need to further analyze the relevance of $\mathrm{AMH}$ assessment in female survivors of cancer. $\mathrm{AMH}$ is obviously not suited to predict fertility in individual patients. However, low AMH levels might indicate a reduced ovarian reserve and thus an increased risk of future premature ovarian failure. This risk cannot be estimated from our study because of the limited observation time. ${ }^{33}$

In addition, chemotherapy-induced amenorrhea might indicate infertility. ${ }^{12}$ After advanced-stage treatment, age $\geq 30$ years at diagnosis had the strongest impact on the risk of sustained amenorrhea 4 years after therapy. Surprisingly, in women younger than age 30 years, a high proportion $(82 \%)$ reported a regular cycle despite escalated BEACOPP therapy. Nonetheless, overall, women face a relevant risk of infertility after BEACOPP chemotherapy. The protective effects of $\mathrm{GnRH}$ analogs observed after intermediate aggressive therapies (four cycles of ABVD or 2+2), ${ }^{22}$ however, could not be documented after BEACOPP therapy for advanced-stage HL in this analysis. Finally, in the cohort of women $\geq 30$ years old at diagnosis, we found a surprisingly high proportion of women with severe menopausal symptoms. ${ }^{18}$ Again, age itself had a stronger negative impact on menopausal symptoms than treatment intensity. Interestingly, only $48.9 \%$ of women with severe symptoms were on hormone medication at the time of the survey. Because menopausal symptoms often substantially affect women's quality of life and might be easy to ameliorate with hormonal replacement therapy, this finding definitively needs further investigation.

In male survivors, we found a high proportion (88.8\%) of oligospermia, indicated by FSH and inhibin B levels, after six to eight cycles of BEACOPP. Even only two cycles of escalated BEACOPP in the $2+2$ regimen induced a marked decrease in the proportion of patients having hormone levels corresponding to proven fertile men (25\%) compared with four cycles of ABVD (50\%). This finding underscores the lower gonadotoxic potential of the ABVD regimen. ${ }^{34-36}$ Only $30 \%$ of male survivors after advanced-stage therapy reported desire for children at 4 years. This observation time might be too short to finally judge on paternity, which was documented in only 12 men (two after natural fertilization and 10 after assisted reproduction). Thus, to maintain the chance for assisted reproduction, cryopreservation of sperm or testicular sperm extraction must be offered before starting aggressive therapy. ${ }^{37}$ Interestingly, levels of testosterone were also within the normal range after escalated BEACOPP therapy, supporting the hypothesis that Leydig cells are more resistant to cytotoxic chemotherapy. ${ }^{11,34,38,39}$ Also, mean aging male symptoms were within the normal range in our analysis.

To summarize, survivors after BEACOPP treatment for advanced-stage disease have the highest risk for symptomatic gonadal dysfunction. However, data directly comparing six to eight cycles ABVD to six to eight cycles of escalated BEACOPP in patients with HL should be generated to exactly quantify risk of treatment options in the context of gonadal toxicity. Until then, the information derived from our analysis may improve both the shared decision-making process regarding individual treatment decisions and the guidance during survivorship.

\section{AUTHORS' DISCLOSURES OF POTENTIAL CONFLICTS OF INTEREST}

The author(s) indicated no potential conflicts of interest.

\section{AUTHOR CONTRIBUTIONS}

Conception and design: Karolin Behringer, Horst Mueller, Indra Thielen, Angelika Diana Eibl, Volker Stumpf, Martin Wiehlpütz, Johannes Rosenbrock, Teresa Halbsguth, Katrin S. Reiners, Thomas Schober, Jorg H. Renno, Michael von Wolff, Katrin van der Ven, Marietta Kuehr, Michael Fuchs, Volker Diehl, Andreas Engert, Peter Borchmann

Provision of study materials or patients: Karolin Behringer, Indra Thielen, Angelika Diana Eibl, Volker Stumpf, Carsten Wessels, Martin Wiehlpütz, Johannes Rosenbrock, Teresa Halbsguth, Katrin S. Reiners, Thomas Schober, Jorg H. Renno, Michael von Wolff, Katrin van der Ven, Michael Fuchs, Volker Diehl, Andreas Engert, Peter Borchmann Collection and assembly of data: Karolin Behringer, Indra Thielen, Angelika Diana Eibl, Volker Stumpf, Carsten Wessels, Martin Wiehlpütz, Johannes Rosenbrock, Teresa Halbsguth, Katrin S. Reiners, Thomas Schober, Jorg H. Renno, Michael von Wolff, Katrin van der Ven, Michael Fuchs, Volker Diehl, Andreas Engert, Peter Borchmann

Data analysis and interpretation: Karolin Behringer, Horst Mueller, Helen Goergen, Indra Thielen, Angelika Diana Eibl, Volker Stumpf, Martin Wiehlpütz, Johannes Rosenbrock, Teresa Halbsguth, Katrin S. Reiners, Thomas Schober, Jorg H. Renno, Michael von Wolff, Katrin van der Ven, Marietta Kuehr, Michael Fuchs, Volker Diehl, Andreas Engert, Peter Borchmann

Manuscript writing: All authors

Final approval of manuscript: All authors

\section{REFERENGES}

1. Borchmann $P$, Topp MS, Behringer $K$, et al: Dacarbazine is an essential component of ABVD in the treatment of early favourable Hodgkin lymphoma: Results of the second interim analysis of the GHSG HD13 trial. Onkologie 33:124-125, 2010 (suppl 6)
2. von Tresckow $B$, Plütschow $A$, Fuchs $M$, et al: Dose-intensification in early unfavorable Hodgkin's lymphoma: Final analysis of the German Hodgkin Study Group HD14 trial. J Clin Oncol 30:907-913, 2012

3. Engert A, Haverkamp $H$, Kobe $C$, et al: Reduced-intensity chemotherapy and PET-guided radiotherapy in patients with advanced stage Hodgkin's lymphoma (HD15 trial): A randomised, open-label, phase 3 non-inferiority trial. Lancet 379:1791-1799, 2012

4. Zebrack BJ, Mills J, Weitzman TS: Health and supportive care needs of young adult cancer patients and survivors. J Cancer Surviv 1:137-145, 2007

5. Gorman JR, Bailey S, Pierce JP, et al: How do you feel about fertility and parenthood? The voices of young female cancer survivors. J Cancer Surviv 6:200-209, 2012 
6. Turner S, Maher EJ, Young T, et al: What are the information priorities for cancer patients involved in treatment decisions? An experienced surrogate study in Hodgkin's disease. $\mathrm{Br} \mathrm{J}$ Cancer 73:222-227, 1996

7. Biasoli I, Franchi-Rezgui $P$, Sibon $D$, et al: Analysis of factors influencing inclusion of $102 \mathrm{pa}$ tients with stage III/IV Hodgkin's lymphoma in a randomized trial for first-line chemotherapy. Ann Oncol 19:1915-1920, 2008

8. Letourneau JM, Ebbel EE, Katz PP, et al: Pretreatment fertility counseling and fertility preservation improve quality of life in reproductive age women with cancer. Cancer 118:1710-1717, 2012

9. Quinn GP, Vadaparampil ST, Gwede CK, et al: Discussion of fertility preservation with newly diagnosed patients: Oncologists' views. J Cancer Surviv 1:146-155, 2007

10. Kiserud CE, Fosså A, Bjøro T, et al: Gonadal function in male patients after treatment for malignant lymphomas, with emphasis on chemotherapy. Br J Cancer 100:455-463, 2009

11. Sieniawski $M$, Reineke $T$, Josting $A$, et al: Assessment of male fertility in patients with Hodgkin's lymphoma treated in the German Hodgkin Study Group (GHSG) clinical trials. Ann Oncol 19: 1795-1801, 2008

12. Behringer $K$, Breuer $K$, Reineke $T$, et al: Secondary amenorrhea after Hodgkin's lymphoma is influenced by age at treatment, stage of disease, chemotherapy regimen, and the use of oral contraceptives during therapy: A report from the German Hodgkin's Lymphoma Study Group. J Clin Oncol 23:7555-7564, 2005

13. Kreuser E, Felsenberg D, Behles $C$, et al: Long-term gonadal dysfunction and its impact on bone mineralization in patients following COPP/ ABVD chemotherapy for Hodgkin's disease. Ann Oncol 3:105-110, 1992 (suppl 4)

14. De Bruin ML, Huisbrink J, Hauptmann M, et al: Treatment-related risk factors for premature menopause following Hodgkin lymphoma. Blood 111:101-108, 2008

15. van Disseldorp J, Faddy MJ, Themmen AP, et al: Relationship of serum antimüllerian hormone concentration to age at menopause. J Clin Endocrinol Metab 93:2129-2134, 2008

16. Andersson AM, Petersen JH, Jørgensen $\mathrm{N}$, et al: Serum inhibin B and follicle-stimulating hormone levels as tools in the evaluation of infertile men: Significance of adequate reference values from proven fertile men. J Clin Endocrinol Metab 89: 2873-2879, 2004

17. Jensen TK, Andersson AM, Hjollund NH, et al: Inhibin $B$ as a serum marker of spermatogenesis: Correlation to differences in sperm concentration and follicle-stimulating hormone levels-A study of 349 Danish men. J Clin Endocrinol Metab 82:40594063, 1997

18. Heinemann $K$, Ruebig $A$, Potthoff $P$, et al: The Menopause Rating Scale (MRS) scale: A methodological review. Health Qual Life Outcomes 2:45, 2004

19. Potthoff $P$, Heinemann LA, Schneider HP, et al: [The Menopause Rating Scale (MRS II): Methodological standardization in the German population]. Zentralbl Gynakol 122:280-286, 2000

20. Moore C, Huebler D, Zimmermann T, et al: The Aging Males' Symptoms scale (AMS) as outcome measure for treatment of androgen deficiency. Eur Urol 46:80-87, 2004

21. Heinemann LA, Moore C, Dinger JC, et al: Sensitivity as outcome measure of androgen replacement: The AMS scale. Health Qual Life Outcomes 4:23, 2006

22. Behringer $\mathrm{K}$, Thielen I, Mueller $\mathrm{H}$, et al: Fertility and gonadal function in female survivors after treatment of early unfavorable Hodgkin lymphoma (HL) within the German Hodgkin Study Group HD14 trial. Ann Oncol 23:1818-1825, 2012

23. La Marca A, Sighinolfi G, Radi D, et al: AntiMullerian hormone (AMH) as a predictive marker in assisted reproductive technology (ART). Hum Reprod Update 16:113-130, 2010

24. Lutchman Singh K, Davies M, Chatterjee R: Fertility in female cancer survivors: Pathophysiology, preservation and the role of ovarian reserve testing. Hum Reprod Update 11:69-89, 2005

25. van Beek RD, van den Heuvel-Eibrink MM, Laven JS, et al: Anti-Mullerian hormone is a sensitive serum marker for gonadal function in women treated for Hodgkin's lymphoma during childhood. J Clin Endocrinol Metab 92:3869-3874, 2007

26. Tsepelidis S, Devreker F, Demeestere I, et al: Stable serum levels of anti-Müllerian hormone during the menstrual cycle: A prospective study in normo-ovulatory women. Hum Reprod 22:18371840, 2007

27. Decanter $C$, Morschhauser F, Pigny $P$, et al: Anti-Müllerian hormone follow-up in young women treated by chemotherapy for lymphoma: Preliminary results. Reprod Biomed Online 20: 280-285, 2010
28. Anderson RA, Cameron DA: Pretreatment serum anti-müllerian hormone predicts long-term ovarian function and bone mass after chemotherapy for early breast cancer. J Clin Endocrinol Metab 96: 1336-1343, 2011

29. Lie Fong S, Laven JS, Hakvoort-Cammel FG, et al: Assessment of ovarian reserve in adult childhood cancer survivors using anti-Müllerian hormone. Hum Reprod 24:982-990, 2009

30. Gracia CR, Sammel MD, Freeman E, et al: Impact of cancer therapies on ovarian reserve. Fertil Steril 97:134-140.e1, 2012

31. Gubbels CS, Kuppens SM, Bakker JA, et al: Pregnancy in classic galactosemia despite undetectable anti-Mullerian hormone. Fertil Steril 91: 1293.e13-e16, 2009

32. Fraisse T, Ibecheole V, Streuli I, et al: Undetectable serum anti-Mullerian hormone levels and occurrence of ongoing pregnancy. Fertil Steril 89: 723.e9-e11, 2008

33. van der Kaaij MA, Heutte $N$, Meijnders $P$, et al: Premature ovarian failure and fertility in long-term survivors of Hodgkin's lymphoma: A European Organisation for Research and Treatment of Cancer Lymphoma Group and Groupe d'Etude des Lymphomes de I'Adulte Cohort Study. J Clin Oncol 30:291-299, 2012

34. Viviani S, Santoro A, Ragni G, et al: Gonadal toxicity after combination chemotherapy for Hodgkin's disease: Comparative results of MOPP vs ABVD. Eur J Cancer Clin Oncol 21:601-605, 1985

35. Bonadonna G: Modern treatment of malignant lymphomas: A multidisciplinary approach? The Kaplan Memorial Lecture. Ann Oncol 5:5-16, 1994 (suppl 2)

36. Kulkarni SS, Sastry PS, Saikia TK, et al: Gonadal function following ABVD therapy for Hodgkin's disease. Am J Clin Oncol 20:354-357, 1997

37. Holoch $P$, Wald M: Current options for preservation of fertility in the male. Fertil Steril 96:286290, 2011

38. Waxman J, Terry $Y$, Wrigley $P$, et al: Gonadal function in Hodgkin's disease: Long-term follow-up of chemotherapy. Br Med J (Clin Res Ed) 285:16121613, 1982

39. Charak BS, Gupta R, Mandrekar $P$, et al: Testicular dysfunction after cyclophosphamidevincristine-procarbazine-prednisolone chemotherapy for advanced Hodgkin's disease: A long-term follow-up study. Cancer 65:1903-1906, 1990 